Revista Signos

2010 / 43

Número Especial

Monográfico $\mathrm{N}^{\circ} 1$

63-76

\author{
Gisele de Carvalho
Universidad del Estado de Río de Janeiro \\ Gisele de Carvalho
Universidad del Estado de Río de Janeiro \\ Brasil
}

\title{
0 gênero 'crítica' em dois veículos de mídia digital: Uma análise sob a perspectiva sistêmico-funcional
}

Resumo: Neste artigo, pretendo destacar as contribuições da análise de gêneros sob a perspectiva sistêmico-funcional (Halliday, 1985; Eggins \& Slade, 1997; Martin \& White, 2005), tomando como exemplo os resultados de um estudo preliminar do gênero "crítica", veiculado em meio digital sítios de revistas de atualidades e em blogues de cinema. As diferenças encontradas na forma como o mesmo gênero do discurso se materializa se justificam não só em função de os textos serem disponibilizados em espaços de circulação distintos, mas também porque as dinâmicas de interação social entre os participantes tanto na extremidade produtora quanto na receptora dos textos se configuram de modo diverso. Os pressupostos da Teoria de Gênero e Registro (Eggins \& Martin, 1996), assim como as categorias analíticas derivadas da Linguística Sistêmico-Funcional, permitem que o pesquisador desenvolva análises refinadas e estabeleça correlações relevantes e seguras entre os propósitos, estágios e características léxico-gramaticais dos gêneros e os contextos social e cultural onde ocorrem.

Palavras-Chave: Linguística sistêmico-funcional, gênero, crítica de filmes.

Recibido: 20-XI-2009 Aceptado: 24-V-2010
Correspondencia: Gisele de Carvalho (giseledecarvalho@oi.com.br). Universidade do Estado do Rio de Janeiro. Rua Oscar Lopes 223, CEP 22755-140, Rio de Janeiro, Brasil. 


\title{
El género 'crítica' en dos publicaciones em medios digitales: Un análisis desde la perspectiva sistémico-funcional
}

Resumen: Este ensayo pretende destacar las contribuciones de los análisis de género en el enfoque sistémico-funcional (Halliday, 1985; Eggins \& Slade, 1997; Martin \& White, 2005), tomando como ejemplo los resultados de un estudio preliminar del género 'crítica', difundida en los sitios digitales de los medios de comunicación para revistas de noticias y blogs de cine. Las diferencias se justifican sobre la base de que los textos están disponibles en diferentes espacios de circulación, sino también porque la dinámica de la interacción social entre los participantes tanto en la producción y en el extremo receptor de los textos se configuran de manera diferente. Los supuestos de la Teoría de Género y Registro (Eggins \& Martin, 1996), así como categorías de análisis derivados de la Lingüística Sistémico Funcional, permiten al investigador desarrollar análisis refinado y establecer correlaciones pertinentes entre los propósitos, las etapas y características léxicogramaticales de los géneros y sus contextos sociales y culturales.

Palabras Clave: Enfoque sistémico-funcional, género lingüístico, crítica de cine.

\section{One genre in two digital media sources: An analysis of the review genre from a systemic-functional perpective}

\begin{abstract}
This paper highlights the contributions of genre analysis under a systemic-functional approach (Halliday, 1985; Eggins \& Slade, 1997; Martin \& White, 2005). The results of a study of a film review sample in webzines and weblogs served as the starting point for this paper. The differences found in the way the texts unfold are related to both the availability of these texts in these different spaces and the distinct forms of social interaction between their producers and their consumers. The basis of the Genre \& Register Theory (Eggins \& Martin, 1996) as well as the analytical categories which stem from Systemic-Functional Linguistics help carry out a detailed analysis and establish relevant correlations between purposes, stages and lexical-grammatical features of genres and the cultural and social contexts in which they occur.
\end{abstract}

Key Words: Systemic-functional linguistics, genre, film review.

\section{INTRODUÇÃO: os pontos de partida ${ }^{1}$}

Não há como negar que a tecnologia amplia os espaços de circulação dos gêneros do discurso. Aqueles que antes estavam restritos, por exemplo, à página impressa do jornal ou da revista ganharam outros veículos no meio digital: portais, sítios, blogues. Junto com o fenômeno, nós, os iniciados na tal inclusão digital, passamos de leitores a usuários e, por isso, a noção de 'interatividade' torna-se chave para compreendermos as novas relações entre produtores e consumidores de textos veiculados no espaço digital (Matheson, 2005). Ao assumirmos nosso papel de usuários, além do controle da navegação, também podemos exercer algum tipo de influência e assim ter algum controle sobre o conteúdo veiculado. Não que não o fizéssemos diante da mídia impressa, afinal somos nós que decidimos se começamos a ler a revista pelo 
fim, que caderno do jornal pegamos primeiro, se assinamos este ou aquele veículo, se nos manifestamos no espaço destinado a cartas dos leitores. Mas me parece que se tornar um usuário é um pouco mais do que apenas uma mudança terminológica -no meio digital a possibilidade de controle do conteúdo veiculado se torna mais concreta e daí decorrem novas práticas discursivas e sociais.

Enquanto leitora e usuária, mas principalmente como professora e pesquisadora de gêneros do discurso, não me é possível ignorar que muitas vezes me deparo com o mesmo gênero materializado de forma acentuadamente diferente no meio digital. Esse espaço é muito maior, mas os robôs de busca o tornam de certa forma pequeno ao colocar à nossa disposição tudo o que foi 'batizado' da mesma forma. Como exemplo, posso citar a ocasião em que solicitei a meus alunos que coletassem exemplares de críticas $^{2}$ de filmes para que pudéssemos conhecer melhor o gênero em questão e partir dali para a análise e produção de outros tipos de resenha mais relevantes para a sua vida universitária. Todos foram ao Google e de lá trouxeram textos veiculados em sítios de revistas especializadas e não-especializadas em cinema, de jornais, de blogues de cinema e de variedades. A constatação de que tínhamos em mãos uma coletânea de textos a princípio pertencentes a um mesmo gênero mas com características distintas entre seus exemplares nos impôs a tarefa da categorização. Optamos, naquele momento, por agrupálos de acordo com as fontes, gesto que permitiu que refinássemos a percepção de semelhanças e diferenças entre os textos coletados. Estávamos diante de textos representativos do mesmo gênero ou de gêneros diferentes? E porque somos profissionais da linguagem, fomos em busca de ferramentas que pudessem nos auxiliar não só a mapear as diferenças e semelhanças encontradas, mas também explicá-las.

Neste evento está a motivação para este artigo. Nele, pretendo destacar as contribuições da análise de gêneros sob a perspectiva sistêmico-funcional, tomando como exemplo os resultados de um estudo do gênero crítica/resenha, disseminado em meio digital nos sítios de duas revistas de atualidades e em quatro blogues de cinema (Carvalho, no prelo). As perguntas que orientam a pesquisa são as seguintes:

- A publicação de resenhas em suportes diferentes mantém ou altera a estrutura genérica e o padrão prosódico avaliativo do gênero?

- Se não há alterações, por que não?

- Se há alterações, quais são, por que ocorrem e o que daí decorre? 


\section{Uma breve descrição do corpus}

Para este estudo, foi compilado um corpus composto de 20 críticas de cinema assim distribuídas: 10 publicadas nos sítios das revistas Veja e Época e 10 postadas em 4 blogues de cinema, a saber: Cinema e Argumento, Diário de Dois Cinéfilos, Hollywoodiano e Museu do Cinema. Nos sítios das revistas, encontram-se as críticas que foram publicadas em papel, sem nenhum tipo de alteração no texto; o que às vezes há de diferente é um link para o trailer do filme. Como a coleta dos textos para compor o corpus começou pelo sítio das revistas, os blogues acabaram sendo escolhidos porque continham resenhas dos filmes que foram avaliados nas revistas (ou seja, cada filme é avaliado duas vezes -na revista e no blogue) e porque não estavam ligados a nenhuma instituição- eram mais 'independentes'. A coleta foi realizada entre janeiro e abril de 2008, antes e depois da premiação do Oscar, pois se o corpus só contivesse textos publicados antes da cerimônia, corria-se o risco de uma incidência incomum de resenhas positivas em função da suposta qualidade dos filmes indicados para concorrer ao prêmio.

\section{As contribuições da análise de gênero sob a perspectiva sistêmico-funcional: $\mathbf{0}$ caso das críticas de filmes ${ }^{3}$}

Comecemos, portanto, por definições de gênero advindas do campo da Linguística SistêmicoFuncional. Eggins e Slade (1997: 56) definem gênero como "atividade com propósito e estágios reconhecidos, na qual os participantes tomam parte/se engajam como membros de uma cultura"; mais recentemente, Martin e White (2005: 32) tornaram a definição mais enxuta: "processo social com estágios e propósitos reconhecidos". Do ponto de vista do analista de gênero e do discurso, essas definições parecem ser particularmente produtivas pois delas podemos depreender que: 1) gêneros são produzidos por atores sociais em seus contextos e são analisáveis em seus aspectos macro-discursivos e micro-textuais: ao reconhecermos os estágios por suas funções e como funcionam de modo a fazer com que o propósito social de gênero seja alcançado, também podemos estabelecer relações entre o funcionamento semântico-discursivo dos diferentes estágios e sua realização léxico-gramatical; e, 2) decorrente da anterior, que o estudo de gêneros assim definidos precisa de ferramentas analíticas que possam dar conta das ações realizadas por meio da linguagem em nossas interações sociais. É também neste sentido que a Linguística Sistêmico-Funcional vem em nosso socorro, ao compreender a linguagem como "um dentre os sistemas por meio dos quais construímos significados" (Halliday, 1985: 3), significados esses que são produzidos e negociados a partir de nossa participação em interações. Ainda segundo o linguista, "esse sistema se organiza na forma de rede de escolhas léxicogramaticais", mas como as escolhas são motivadas, elas estão interligadas com os significados 
-ideacionais, interpessoais e textuais- representados na linguagem:

"Isso implica que a vida social requer a negociação de um mundo ideacional compartilhado. Ao mesmo tempo, ela requer uma renegociação contínua de nossos lugares naquele mundo: quem somos, como nos relacionamos com outras pessoas nele, e como nos sentimos a esse respeito. No processo de negociação daquelas realidades ideacionais e interpessoais, também precisamos negociar formas de falar sobre aquele mundo: que tipos de textos podemos construir para representar os significados ideacionais e interpessoais" (Eggins \& Slade, 1997: 50-51).

A abordagem sistêmico-funcional compreende a linguagem como um recurso social para expressar esses três significados ao mesmo tempo, significados esses que "podem ser identificados em unidades linguísticas de todos os tamanhos: no léxico, no sintagma, na oração, na frase e no texto" (Eggins \& Slade, 1997: 48).

Um aspecto importante para os analistas de gênero segundo a perspectiva sistêmico-funcional está na compreensão de que as convenções sociais estabelecem como devemos nos comportar discursivamente a fim de levar a cabo nossas ações. Estas se encontram em estreita relação com o Contexto de Cultura ${ }^{4}$. Ao longo da vida escolar, por exemplo, vamos apreendendo como certos textos se desenvolvem -como começam e progridem até chegarem ao final, até realizarem seu propósito. Essa experiência nos faz poder prever o que começa com 'Era uma vez..., que a frase Temporão disse também que o número de casos de gripe H1N1 deve aumentar por causa do inverno' foi, provavelmente, retirada do meio de uma notícia e que 'Atenciosamente' seguido de uma assinatura indicaria o fim de uma carta mais formal. Assim, vamos ampliando nossa socialização genérica e essa experiência nos prepara tanto para reconhecermos como as interações sociais se processam, quanto para podermos agir de acordo. Desta forma, passo a passo, a cada constituinte funcional que vamos agregando ao anterior com vistas a consumar o propósito social de uma interação, vamos atualizando a organização do gênero em que atuamos, de acordo com nosso conhecimento do contexto de cultura.

A forma como um texto se organiza constitui sua 'estrutura esquemática' que, por sua vez, realizaria o potencial do gênero a que pertence -a estrutura genérica potencial (Eggins, 1994). Nem todos os textos pertencentes ao um mesmo gênero se desenvolvem exatamente do mesmo modo, mas certos elementos são necessários para que o propósito do gênero seja alcançado; assim há elementos canônicos, obrigatórios, e outros que são opcionais; a identificação dos primeiros nos torna capazes de decidir se a estrutura esquemática do texto x' o faz um candidato a representante do gênero $X$.

A partir desses parâmetros, procedemos à análise de como a informação contida nas resenhas 
se organiza e, dessa forma, chegamos à conclusão de que os seguintes estágios são recorrentes: 1) classificação do filme segundo o gênero a que pertence; 2) resumo do enredo do filme; 3 ) avaliação (de diferentes aspectos) do filme; 4) recomendação para o leitor. Estes elementos correspondem aos da estrutura genérica potencial de resenhas. No entanto, há variação na ordem de ocorrência dos estágios nos textos analisados, assim como em relação ao tipo de elementos opcionais (como por exemplo, inserção de dados biográficos do diretor ou ator/atriz ou discussão do tema abordado no filme), sendo que as críticas dos blogues apresentaram um número maior de estágios diferentes.

As escolhas léxico-gramaticais, por serem motivadas, não ocorrem no vácuo. "Todo uso de linguagem tem um contexto. As características 'textuais' permitem que o discurso seja coerente não só com ele mesmo, mas também com seu contexto de situação” (Halliday \& Hasan, 1985: 45), ou seja, o contexto mais imediato da ocorrência de um texto. A Linguística SistêmicoFuncional nos oferece aqui a noção de Registro e suas variáveis 'campo', 'relações' e 'modo'5, como ponto de partida para a descrição do que mais imediatamente tem impacto em nossas escolhas léxico-gramaticais: em que área do conhecimento situamos nossa contribuição, com que propósito comunicativo o fazemos, que papéis sociais desempenhamos (por exemplo, temos mais ou menos controle sobre o outro?, o nosso relacionamento é marcado por distância ou proximidade social?), qual o papel da linguagem em nossas interações, de que canais e meios dispomos ao fazer uso da linguagem. Estamos, portanto, diante de uma abordagem para o estudo e descrição da linguagem que prioriza a correlação sistemática, mas probabilística, entre texto e contexto: o texto traz em si um contexto e do primeiro pode-se deduzir o segundo; o contexto permite prever como os significados manifestos no texto estarão linguisticamente representados (Eggins \& Martin, 1996). Esta correlação também nos permite dois caminhos metodológicos, um ascendente -do texto para o contexto- e outro descendente. Neste trabalho, procedemos da segunda forma.

Voltemos então ao gênero crítica de filme. Em relação à variável 'campo', as críticas oferecem uma avaliação crítico-estética de um filme recentemente lançado no circuito. Este propósito vale tanto para o leitor (que procura a leitura de uma resenha como um guia para sua próxima ida ao cinema ou para se manter informado acerca dos últimos lançamentos do mercado cinematográfico), como também para o resenhista, que assiste o filme sabendo que terá de produzir um texto que, além de conter suas impressões acerca do filme, seja capaz de dar aos leitores uma idéia resumida de uma narrativa que não pode ter seu final revelado. Um outro propósito do gênero é o de dar visibilidade a uma nova produção. No caso da revista, este está atrelado à função do editor da seção de jornalismo cultural que, ao pautar várias resenhas para uma determinada edição, opta pela publicação de uma fração delas. Com exceção das decisões 
baseadas apenas na formatação da revista (um espaço de sobra que precisa ser preenchido), a publicação de uma resenha tende a levar em conta algum dos critérios normalmente utilizados para se definir o que deve virar notícia. No caso do blogue, além dos propósitos comunicativos já elencados, também verifica-se o objetivo de manter viva a discussão sobre cinema entre o blogueiro e seus leitores.

Quanto à variável 'relações', pode-se depreender que os participantes no gênero veiculado no sítio da revista são os leitores, o resenhista (em geral um jornalista) e o editor da seção cultural. Em linhas gerais, o leitor não é um especialista em crítica cinematográfica, ao passo que o editor e o resenhista, se não o são por formação, acabam por sê-lo em função dos papéis que desempenham. A relação estabelecida entre o primeiro e os outros dois é desigual, pois a opinião emitida sobre a qualidade do filme e a escolha de uma determinada resenha para ser publicada cabem ao resenhista e ao editor, respectivamente. Em outras palavras, ao leitor cabe aderir a um acordo tácito que diz que a leitura de uma resenha começa pela aceitação da posição do jornalista/crítico como alguém abalizado para emitir um parecer. Nos blogues de cinema, a descrição da variável 'relações toma' um feitio diferente: o blogueiro -o autor do blogue- é facilmente identificado em seu perfil e em geral se define como um amante de cinema, podendo ser um profissional da área ou não; além dos usuários que acessam o blogue para apenas ler as resenhas, há também os que deixam lá seus comentários; estes são passíveis de identificação mesmo que não se apresentem por meio de seu nome verdadeiro, visto que há uma persona discursiva inscrita nas mensagens, que por sua vez pode ser associada a um nome ou um apelido, muitas vezes acompanhados de foto. Todos os que ali interagem dividem um mesmo espaço discursivo e de certa forma se (re)conhecem.

Partindo da variável 'modo', vê-se que a linguagem é constitutiva do gênero resenha e que o tipo de texto predominante é persuasivo, ensejando inclusive um comando explícito ou implícito: não veja/veja este filme ou, então, veja este filme apesar das ressalvas apontadas. 0 texto utiliza canal gráfico em combinação com elementos de apelo visual, como cenas do filme, com destaque para aquelas que trazem o ator ou atriz principal.

Desta descrição, podemos prever que os textos dos blogues poderão conter linguagem menos técnica já que blogueiro se coloca como um generalista ou diletante (enquanto o jornalista fala do lugar de especialista, de conhecedor do campo). Os blogues também podem evidenciar mais marcas de interação em vista das diferenças apontadas na variável relações: a menor discrepância nas relações de poder entre os interagentes no blogue e a maior possibilidade de contato favoreceriam o uso de linguagem mais propício à troca.

Resta-nos, então, verificar se as previsões se concretizam nos textos das críticas. Para tal, op- 
tamos por investigar como se avalia, já que este parece ser o principal propósito comunicativo das resenhas e porque a avaliação é um estágio recorrente nos textos. Além disso, a análise do Registro indica que as possíveis diferenças no uso de recursos lingüístico-discursivos se encontrariam na expressão de significados interpessoais. Portanto, escolhemos como categoria de análise textual a 'Atitude', um dos três domínios semânticos do sistema da Avaliatividade (Martin, 2000; Martin \& Rose, 2003; Martin \& White, 2005), que contempla os "recursos semânticos usados para negociar emoções, julgamentos e valores, ao lado daqueles usados para amplificar e criar comprometimento com estas avaliações" (Martin, 2000: 145). 0 sub-sistema da Atitude inclui os recursos semântico-discursivos usados para expressar 'Afeto' - "construir reações emocionais”-, 'Julgamento' - “construir avaliações morais de comportamento”- e 'Apreciação' -construir a qualidade 'estética' de textos/processos semióticos e fenômenos naturais (Martin, $2000)^{6}$.

Apesar de estudos anteriores sobre críticas (Berbare, 2002; Carvalho, 2006; Hyland, 2000; Machado, Lousada \& Abreu-Tardelli, 2004) se dedicarem a questões específicas e partirem de modelos teóricos distintos, todos indicam que a opinião manifesta não tem marcação explícita da subjetividade do resenhista (por exemplo, com expressões como 'na minha opinião', 'acho/ acredito que') e que o crítico também busca avaliar de forma mais objetiva. Revelam também que o objeto das resenhas parece restringir o tipo de atitude que nelas se encontra; ou seja, por tratar-se da avaliação de um produto do campo das artes e/ou da academia e do desempenho dos profissionais envolvidos em sua realização, a expressão de avaliação por meio de Apreciação e de Julgamento ocupa lugar de destaque, legando praticamente à inexistência a categoria de Afeto.

Em virtude do resultados desses estudos, tomaríamos como ponto de partida para a análise dos textos do corpus as categorias de Apreciação e Julgamento apenas; entretanto, a simples leitura das críticas publicadas nos blogues já apontavam para a necessidade de não descartar a categoria de Afeto. Aqui estão dois fragmentos que demonstram que a avaliação expressa acerca do filme tem como fonte a emoção de quem avalia:

1) Espero do fundo do coração que vocês se divirtam tanto quanto eu me diverti e ri e vibrei durante o filme. Não deixem de assistir (http://cinemaeargumento.wordpress.com)

2) Eu ainda passo pela adolescência e sinto como é, o que fez eu me apaixonar ainda mais pelo filme e pela sua protagonista (http://diariodedoiscinefilos.blogspot.com)

Assim, em função dos dados que o corpus oferece, foi necessário manter todas as três categorias do domínio semântico da Atitude.

A fim de não ocupar espaço da discussão com a simples inserção dos textos analisados, há 
aqui dois fragmentos das críticas do filme Juno para que se tenha uma idéia do quanto eles são distintos. 0 primeiro foi retirado do sítio da Revista Veja, edição 2046, de 6 de fevereiro de 2008, da autoria de Isabela Boscov; o segundo foi escrito por Otávio Almeida e retirado do blogue Hollywoodiano (http: / /www.hollywoodiano.com/), onde foi publicado em 27 de janeiro de 2008.

\section{Doce sem ser adocicado}

Juno, uma das criações mais originais do cinema independente, merece mais do que suas quatro indicações ao Oscar: merece ser visto.

Algumas adolescentes se expressam por meio das roupas que vestem, outras montam blogs, outras ainda fazem álbuns de colagem. Já a personagem-título de Juno (Estados Unidos/Canadá, 2007) dirige toda a sua criatividade para o que diz, e como o diz. Juno é incapaz de deixar uma palavra quieta no seu canto: todas elas têm de ser modificadas ou arranjadas em combinações inovadoras e improváveis. É condizente então que os diálogos do filme (já em exibição em esquema de pré-estréias, e com entrada em circuito prevista para o dia 22) fervilhem de imaginação - e que, na interpretação da notável Ellen Page e dos atores igualmente inteligentes que the fazem companhia, eles ricocheteiem para lá e para cá como balas num tiroteio. Oportunidade para essa fuzilaria não é o que falta na história. [...]

Juno

Quem me conhece, sabe o quanto eu ando cético e decepcionado em relação ao cinema atual. Quem me conhece, também sabe o quanto eu me encanto com filmes grandiosos, épicos... Justamente numa hora em que Hollywood e a maioria da crítica especializada tentam fabricar falsas obras-primas, o ótimo (e ainda novo) diretor Jason Reitman vem com esse Juno (Juno, 2007) e me deixa sem palavras. Minha fé no bom cinema está de volta.

Alguns filmes estão além de qualquer elogio ou palavra. Por mais que eu tente decifrar e explicar aqui os encantos proporcionados por Juno, isso significaria horas e horas de enrolação e não chegaríamos a lugar algum. Acho que basta dizer que o filme de Jason Reitman atingiu em cheio o meu coração. É isso. Estou apaixonado por Juno. Alguns filmes têm esse poder. Um endereço certo. [...]

A análise das resenhas publicadas nos sítios das revistas indica que a prosódia atitudinal se mantém fiel ao padrão do gênero: há uma forte tendência ao elogio, não há avaliação por meio de Afeto e há mais índices de Apreciação do que de Julgamento. Em outras palavras, o espaço destinado às críticas nas revistas e em seus sítios tende a dar visibilidade a bons filmes; além disso, avalia-se mais o filme do que o desempenho de quem dele participa, seja na frente ou atrás das câmeras. Ao não avaliar por meio do filtro da emoção, o crítico constrói uma imagem 
discursiva de quem privilegia a análise objetiva, possivelmente buscando conferir credibilidade à sua avaliação.

As críticas publicadas em blogues diferem daquelas em dois sentidos: em primeiro lugar, elas também contem índices de Afeto, apesar de apresentarem mais avaliação por meio de Apreciação do que Julgamento, neste aspecto replicando o padrão atitudinal das resenhas vistas acima. Além disso, quatro das críticas escritas por blogueiros traziam avaliações negativas de aspectos pontuais do filme que analisavam.

Cabe-nos agora tentar explicar a diferença encontrada. Os sítios das revistas Veja e Época não são muito diferentes das revistas impressas, com exceção da existência de links para os blogues de seus colunistas. Além da seção de cartas (que, como sabemos, não contempla todas as recebidas, mas somente aquelas selecionadas), este é o único outro espaço que pode ser ocupado pelo leitor.

Segundo Scalzo (2003), a revista se encontra no meio termo entre, por exemplo, a tv e a internet: elas não falam para um todo, como a primeira, nem permitem que o leitor selecione apenas o que quer, como a segunda, já que o repertório na rede é quase ilimitado. Elas falam para o seu público, especialmente o assinante, grupo cujos interesses são identificados por meio de pesquisas qualitativas e quantitativas. Ainda de acordo com a autora, a revista estaria respondendo a uma necessidade de seus leitores ao provê-los de:

"Mediadores que analisem, selecionem, recortem e ofereçam informações qualificadas ao público. Afinal, quem lê as seções ou revistas especializadas em cinema deseja conhecer a opinião de qualquer pessoa ou a daqueles críticos que já conquistaram sua confiança?” (Scalzo, 2003: 51).

Infere-se deste relato, portanto, que o contrato entre quem escreve e quem lê assegura ao jornalista o lugar de especialista, aquele que sabe, que está bem informado e que, para manter a credibilidade pressuposta e/ou angariada, ele emite sua opinião por meio de Apreciação e Julgamento, demonstrando um posicionamento objetivo diante do filme que avalia. Estes dois sub-tipos também servem para estabelecer uma distância social adequada à hierarquia presente no contrato e para demonstrar como o veículo concebe seu papel perante seu público (segundo a ótica da jornalista citada): os valores de uns poucos são disseminados para outros muitos ${ }^{7}$.

0 mesmo não acontece em relação à interação nos blogues de cinema. Sua organização é basicamente padronizada, constituindo-se de mensagens (ou posts) organizadas cronologicamente (a mais recente é visualizada em primeiro lugar), seguidas de um link para os comentários dos leitores. Alguns blogues também possuem uma ferramenta, conhecida como trackback, que permite que seus posts sejam comentados em outro blogue (Oliveira, 2002). Ou seja, uma críti- 
ca pode ser comentada no mesmo blogue onde foi publicada e também em outros. Além disso, os quatro blogues aqui analisados contêm uma coluna onde se encontram links para outros blogues de cinema e todos os quatro se referem uns aos outros neste espaço. Desta descrição, podemos concluir que os blogues são ambientes que privilegiam o diálogo.

Segundo Komesu (2005: 198) os blogues se caracterizam por ser "um modo de enunciação fundado na publicização de si" e o blogueiro é estimulado a continuar produzindo em função da presença dos comentários. Assim, quanto mais registros de que foi lido, mais motivação tem para escrever e postar suas resenhas. 0 blogue tem marcas de subjetividade muito claras na sua composição: o blogueiro responsável pela publicação das críticas fala para uma comunidade da qual faz parte e na qual quer se destacar, em um espaço compartilhado por todos que ali interagem. Além disso, a possibilidade e o desejo de tornar público um 'eu' gerariam uma maior necessidade de marcar quem fala, de personalizar o discurso, não só por meio da primeira pessoa do singular, mas também por meio de avaliação de Afeto. Dentre as três categorias do domínio semântico da Atitude esta é que se considera mais pessoal e interpessoal, o que também atende ao compromisso de manter a interação entre diferentes sujeitos que no blogue se expressam. Como nos diz Recuero (2004: 3):

“É importante a percepção do discurso pessoal nos blogs porque ele é o fundamento da interação. Para que exista interação é necessário que os interagentes se reconheçam enquanto sujeitos na relação comunicativa”.

Portanto, ao encaminhar sua opinião acerca de um filme usando também a avaliação de Afeto, o blogueiro não só enfatiza um ponto de vista pessoal, mas também marca explicitamente sua subjetividade para tentar estimular que a interação entre os diferentes participantes se mantenha.

\section{CONCLUSÃO: voltando ao ponto de partida}

A análise de gêneros baseada em uma abordagem originária da Linguística Sistêmico-Funcional aponta a importância de estudar e descrever o que efetivamente fazemos por meio do uso dos recursos da língua em interações sociais. Com base nos pressupostos teóricos e metodológicos da Teoria de Gênero e Registro, podemos submeter um texto à análise para verificar se ele se organiza segundo as convenções de uma determinada atividade social e seus propósitos comunicativos. Também podemos investigar suas características léxico-gramaticais e relacioná-las tanto aos estágios que realizam o gênero, quanto aos diferentes aspectos de sua configuração contextual, assim cumprindo a tarefa de correlacionar texto e contexto da cultura e da situação. 0 modelo sistêmico-funcional põe à disposição dos pesquisadores de gênero uma multipli- 
cidade de possibilidades analíticas que têm como fundamento a interrelação entre linguagem e vida social. É abrangente e detalhado ao mesmo tempo, pois procura descrever os recursos léxico-gramaticais, discursivos e genéricos em sua relação com o contexto sociocultural.

A pergunta derivada do evento que mobilizou este estudo ainda precisa ser respondida. Estamos diante do mesmo gênero do discurso disponibilizado em suportes diferentes no meio digital ou estamos diante de gêneros diferentes? As análises do corpus apontam mais semelhanças do que diferenças tanto na estrutura genérica quanto na prosódia avaliativa das resenhas. Neste sentido, sim, os textos disponibilizados no sítio das revistas e nos blogues são exemplares do gênero resenha e as diferenças identificadas se explicam pela relativa estabilidade dos gêneros (Bakhtin, 1979/1992), que podem variar tanto segundo os contextos socioculturais onde ocorrem ou de acordo com a passagem do tempo.

Talvez o tempo de que dispúnhamos para perceber as mudanças nos gêneros passasse um pouco mais lentamente. Talvez certas mudanças nunca chegassem à página impressa. De fato, onde, há uns 15 anos atrás, encontraríamos os textos que se encontram hoje nos blogues de cinema? Eles não estariam mais para a conversa no bar, entre amigos, discutindo o filme assistido? Parece-me, então, que a tecnologia de nossos dias, de certo modo, tanto permite o surgimento de novas formas dos velhos gêneros, como acentua a nossa percepção da sua instabilidade -porque tudo isso ocorre ao mesmo tempo.

\section{REFERÊNCIAS BIBLIOGRÁFICAS}

Bakhtin, M. (1979/1992). Os gêneros do discurso. Em M. E. Pereira (Trad.), Estética da criação verbal (pp. 277-287). São Paulo: Martins Fontes.

Berbare, A. (2002). Crítica de cinema: Caracterização do gênero para projetos de produção escrita na escola. Em M. A. Lopes-Rossi (Org.), Gêneros discursivos no ensino de leitura e produção de textos (pp. 41-58). Taubaté-SP: Cabral Ed. e Livraria Universitária.

Carvalho, G. (2006). Críticas de livros: Um breve estudo da linguagem da avaliação. Linguagem em (Dis)curso. Tubarão, 6(2), 179-198.

Carvalho, G. (no prelo). Atitudes diferentes: Quando o blogueiro e o jornalista escrevem sobre cinema. Congresso da Associação de Lingüística Sistêmico-Funcional da América Latina, ALSFAL, 4, 2008. SC. Anais do $4^{\circ}$ Congresso da Associação de Lingüística SistêmicoFuncional da América Latina, Florianópolis, Brasil.

Eggins, S. (1994). An introduction to Systemic Functional Linguistics. London: Continuum International Publishing Group Ltd. 
Eggins, S. \& Martin, J. (1996). Genres and registers of discourse. Em T. van Dijk (Ed.), Discourse: A multidisciplinary introduction (pp. 232-256). London: Sage.

Eggins, S. \& Slade, D. (1997). Analysing casual conversation. London: Cassel.

Halliday, M.A.K. (1985). Introduction to Functional Grammar. London: Edward Arnold.

Halliday, M.A.K. \& Hasan, R. (1985). Language, context and text: Aspects of language in a social-semiotic perspective. Oxford: Oxford University Press.

Hyland, K. (2000). Disciplinary discourses-social interactions in academic writing. Harlow, U.K.: Pearson Education Limited.

Komesu, F. C. (2005). Entre o público e o privado: Um jogo enunciativo na constituição do escrevente de blogs na internet. Tese apresentada ao Departamento de Lingüística do Instituto de Estudos da Linguagem da Universidade Estadual de Campinas. Campinas (SP), Brasil.

Machado, A., Lousada, E. \& Abreu-Tardelli, L. (2004). Resenha. São Paulo: Parábola.

Martin, J. (2000). Beyond Exchange: APPRAISAL Systems in English. Em S. Hunston \& G. Thompson (Eds.), Evaluation in Text: Authorial Stance and the Construction of Discourse (pp. 142175). Oxford: Oxford University Press.

Martin, J. \& Rose, D. (2003). Working with discourse: Meaning beyond the clause. New York: Continuun International Publishing Group Ltd.

Martin, J. \& White, P. (2005). The language of evaluation. New York: Palgrave Macmillan.

Matheson, D. (2005). Media discourses: Analysing Media Texts. Berkshire: Open University Press.

Oliveira, R. (2002). De onda em onda: A evolução dos ciberdiários e a simplificação das interfaces [em línea]. Disponível em: http://www.bocc.ubi.pt

Recuero, R. (2004). O interdiscurso construtivo como característica fundamental dos webrings. Texto [em línea]. Disponível em: http://pontomidia.com.br/raquel/intextoraquelrecuero.pdf

Scalzo, M. (2003). Jornalismo de revista. São Paulo: Editora Contexto.

\section{NOTAS}

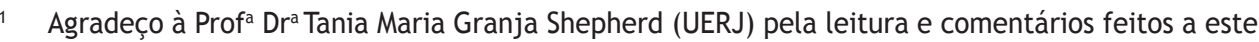
artigo.

2 Os termos crítica e resenha serão usados como sinônimos neste artigo.

3 Esta seção se organiza da seguinte forma: cada pressuposto teórico, conceito ou categoria de análise explicitados é seguido pelos resultados das análises dos textos do corpus. 
4 Halliday e Hasan (1985) e Eggins e Martin (1996) para explanações mais detalhadas acerca das noções de Contexto de Cultura e Contexto de Situação.

5 Eggins (1994: 52-74) para uma descrição detalhada das variáveis campo, relações e modo.

6 Em função dos objetivos deste artigo e da limitação de espaço, não é possível discorrer sobre as diferentes categorias e sub-categorias que compõem o domínio semântico da Atitude neste artigo, o que pode ser encontrado nas fontes indicadas.

7 A desconstrução da naturalização das posições discursivas seria objeto de uma longa discussão que, infelizmente, não cabe neste artigo. Recomendamos a leitura dos trabalhos oriundos da Análise Crítica do Discurso. 